\title{
Low Noise and High Gain RF MOSFETs on Plastic Substrates
}

\author{
H. L. Kao ${ }^{1}$, Albert Chin ${ }^{2,}$, C. C. Huang ${ }^{1}$, B. F. Hung ${ }^{1}$, K. C. Chiang ${ }^{1}$, Z. M. Lai ${ }^{1}$, S. P. McAlister ${ }^{3}$ and \\ C. C. $\mathrm{Chi}^{4}$ \\ ${ }^{1}$ Nano Science Tech. Center, Dept. of Electronics Eng., Nat'l Chiao-Tung Univ., Univ. System of Taiwan, \\ Hsinchu, Taiwan, ROC \\ ${ }^{2}$ SNDL, Dept. of Electrical \& Computer Eng., National University of Singapore, Singapore 119260 \\ *on leave from Nano Science Tech. Center, Univ. System of Taiwan- NCTU albert achin@ hotmail.com \\ ${ }^{3}$ National Research Council of Canada, Ottawa, Canada \\ ${ }^{4}$ Dept. of Physics, National Tsing Hua Univ., Hsinchu, Taiwan, ROC
}

\begin{abstract}
A low minimum noise figure $\left(N F_{\min }\right)$ of $1.2 \mathrm{~dB}$ and high associated gain of $12.8 \mathrm{~dB}$ at $10 \mathrm{GHz}$, were measured for $0.18 \mu \mathrm{m}$ RF MOSFETs on plastic, made by substrate thinning $(\sim 30 \mu \mathrm{m})$, transfer and bonding. The performance can be further improved to $0.96 \mathrm{~dB} N F_{\min }$ and $14.1 \mathrm{~dB}$ associated gain at $10 \mathrm{GHz}$, under applied tensile strain, using flexible Si on plastic. A $3.5 \mathrm{nH}$ inductor on plastic showed a $55 \%$ higher $Q$-factor with a wider frequency range, compared with that on a Si substrate.
\end{abstract}

Index Terms - RF Noise, associated gain, MOSFET, plastic.

\section{INTRODUCTION}

The integration of RF ICs on plastic substrates is a useful technology for RF ID [1]-[2] and wireless display applications. Plastic substrates are not very lossy and are highly insulating (resistivity $\sim 10^{8}-10^{9} \Omega-\mathrm{cm}$ ) - this is ideal for RF IC integration. In contrast, VLSI-standard $\mathrm{Si}$ substrates have a much lower resistivity of $10 \Omega-\mathrm{cm}$; this results in large RF substrate loss and poor Q-factors [3]-[12]. The performance of RF passive devices on $\mathrm{Si}$ can be improved by integration on highresistivity $\mathrm{Si}$ substrates [9], using MEMS [10]-[12] or ionimplant translated semi-insulating $\left(10^{6} \Omega-\mathrm{cm}\right) \mathrm{Si}$ technology [3]-[8]. This improvement is traded-off by the increased cost of added mask and process steps, or package costs. A challenge for integrating RF ICs on plastic is that high performance transistors are required and need to be transferred from their Si substrates, and mounted on plastic with little performance degradation. Integration with high performance RF passive devices on the plastic substrate demands that the $\mathrm{Si}$ substrate of the RF transistors be thinned. In this paper we report a $\mathrm{Si}$ substrate thinning method and successfully transfer devices onto plastic. The $30 \mu \mathrm{m}$ thick Si RF MOSFETs on plastic showed low minimum noise figure $\left(N F_{\min }\right)$ of $1.2 \mathrm{~dB}$ and high associated gain, $12.8 \mathrm{~dB}$, at $10 \mathrm{GHz}$. This excellent $\mathrm{RF}$ performance on plastic is comparable with that on standard Si substrates [13]-[14]. Further improvement to $0.96 \mathrm{~dB} N F_{\text {min }}$ and $14.1 \mathrm{~dB}$ associated gain at $10 \mathrm{GHz}$ is obtained under applied tensile strain [15], using flexible $\mathrm{Si}$ (30 $\mu \mathrm{m}$ thick) on plastic. The advantage of integrating RF devices on plastic is also evident from a $3.5 \mathrm{nH}$ inductor: the Q-factor is improved by $55 \%$ over a wide frequency range for a device on plastic, compared with one on $\mathrm{Si}$. The devices with excellent low noise and high gain, combined with high-Q inductors are suitable for low-noise ultra-wide band (UWB) (3.1-10.6 GHz) applications.

\section{EXPERIMENTAL PROCEDURE}

Low-cost, highly-insulating polyethylene substrates were used in this study, having a resistivity of $10^{8}-10^{9} \Omega-\mathrm{cm}$. The multiple-gate-finger $(6,16$, and 32) $0.18 \mu \mathrm{m}$ MOSFETs were designed to reduce the gate-resistance-generated thermal noise [13]-[14], which is traded-off by the increase in DC power consumption. The Si substrate of the fabricated MOSFETs was thinned down from $300 \mu \mathrm{m}$ (6 mil) to $30 \mu \mathrm{m}$, using Inductive-Coupled Plasma (ICP) dry etching followed by wet chemical etching. The ICP etching provides accurate thickness-control down to $30 \mu \mathrm{m}$ and below. The thinned devices were glued onto the plastic for DC, RF and noise testing. Fig. 1(a) shows an image of the fabricated die on transparent plastic (holding by hand- the background), where an enlarged image is shown in Fig. 1(b). The transparent substrate reveals the surface of a wooden table as the background. To use the advantages of the plastic, we fabricated a $3.5 \mathrm{nH}$ inductor on it using $2 \mu \mathrm{m}$ thick Al. For comparison a $3.5 \mathrm{nH}$ inductor was also fabricated in a VLSIstandard 1-Poly-6-Metal (1P6M) foundry process. In Fig. 1(c) shows an image of an inductor on plastic, where all process temperatures were kept below $100^{\circ} \mathrm{C}$.

The device characteristics were measured using HP4155C for DC, HP8510C network analyzer for S-parameter and ATN-NP5B for noise measurements.

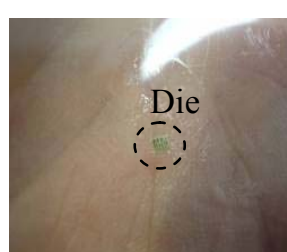

(a)

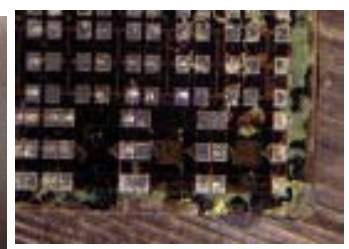

(b)

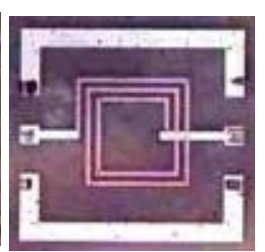

(c)
Fig. 1. (a) Image of a $30 \mu \mathrm{m}$ thick RF MOSFET die on transparent plastic. (b) Enlarged image of a die of multiple-gate $0.18 \mu \mathrm{m}$ MOSFETs on plastic. (Background is the surface of a wooden table.) (c) Image of an inductor fabricated on plastic. 


\section{RESULTS AND DISCUSSION}

\section{A. Q-factor of a passive inductor fabricated on plastic}

Figure 2 shows the measured inductance and Q-factor for a $\sim 3.5 \mathrm{nH}$ inductor on plastic. For comparison, the data for a similar $3.5 \mathrm{nH}$ inductor on VLSI-standard $\mathrm{Si}$ is also shown. The Q-factor of the inductor is improved by 55\% from 6.4 (on $\mathrm{Si}$ ) to 10 (on plastic). The resonance frequency is also improved from $9 \mathrm{GHz}$ (on $\mathrm{Si}$ ) to $12 \mathrm{GHz}$ (on plastic). These improvements are similar to our reported ion-implant translated semi-insulating $\mathrm{Si}$ technology [4]. However, the area cost of plastic substrates is negligible compared with that of processed 8-in Si wafers using $0.18 \mu \mathrm{m}$ technology. The low cost and high RF performance of passive devices are important advantages for plastic electronics, in addition to the optical transparency.

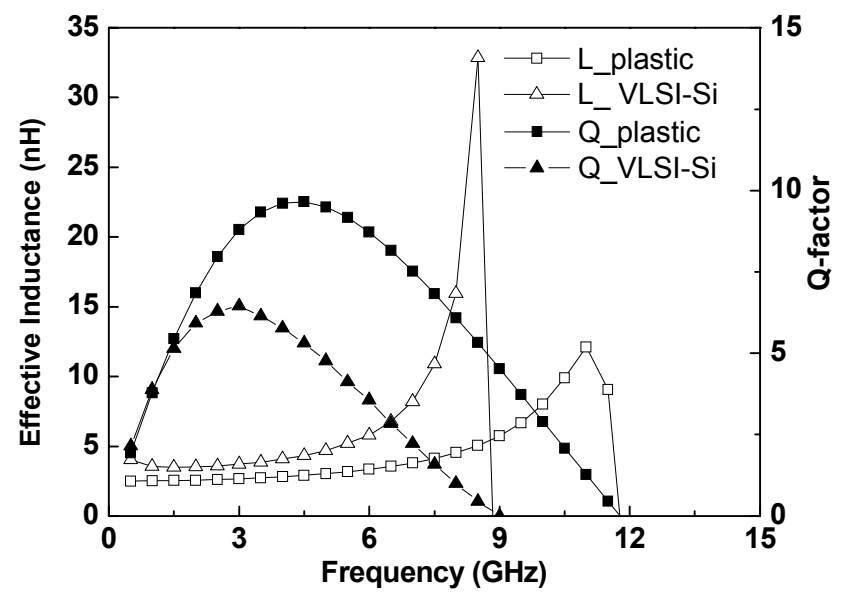

Fig. 2. The inductance and Q-factor of a $\sim 3.5 \mathrm{nH}$ inductor on plastic and VLSI-standard 1P6M Si. The maximum temperature for fabricating the inductor on plastic was $100^{\circ} \mathrm{C}$.

\section{B. DC characteristics of nMOSFETs on plastic}

For the active transistors on plastic we first measured the DC $I_{d}-V_{d}$ characteristics. Fig. 3 shows the $I_{d}-V_{\mathrm{d}}$ characteristic of $0.18 \mu \mathrm{m}$ nMOSFETs with 6 gate fingers on plastic, where the $\mathrm{Si}$ substrate had been thinned down to $30 \mu \mathrm{m}$. For comparison, data for similar devices on a VLSI-standard Si substrate are also displayed. The almost identical $I_{d^{-}} V_{d}$ characteristics in Fig. 3, and $I_{d}-V_{g}$ characteristics (not shown), suggest that the process of thinning down the Si substrate to $30 \mu \mathrm{m}$, then transferring and bonding it onto plastic, produced little degradation of the 6 -finger $0.18 \mu \mathrm{m}$ nMOSFETs. Similar observations were found for the DC $I_{d^{-}} V_{d}$ and $I_{d^{-}} V_{g}$ characteristics for 16- and 32-finger devices, suggesting that they are also suitable for further RF applications and examination.

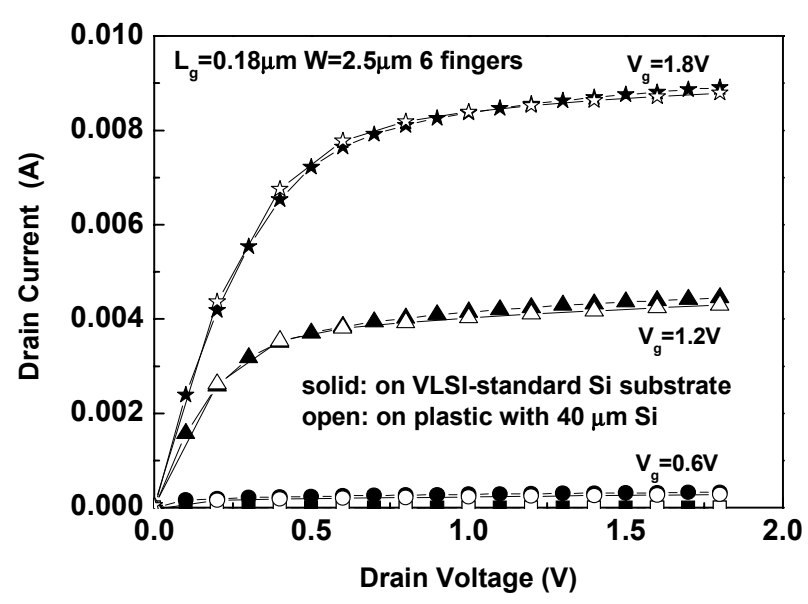

Fig. 3. Measured DC $I_{d}-V_{d}$ characteristics for 6-gate-finger 0.18 $\mu \mathrm{m}$ RF MOSFETs on plastic, where the Si had been thinned down to $30 \mu \mathrm{m}$ (open symbols). The $I_{d}-V_{d}$ of similar devices on VLSI-standard substrates, before thinning down and bonding, is included for comparison (solid symbols).

\section{S-parameters and $N F_{\text {min }}$ of nMOSFETs on plastic}

In Figure 4(a) we show the S-parameters of a 6-gate-finger $0.18 \mu \mathrm{m}$ RF MOSFET on plastic, where the Si substrate had been thinned down to $30 \mu \mathrm{m}$. For comparison, the measured S-parameters of a device on a VLSI-standard substrate are also shown. There is little $S_{21}$ gain degradation as well as little change in the reverse isolation $S_{12}$. The changes in both $S_{11}$ and $S_{22}$ are due to the increased substrate impedance when using plastic. The plastic helps reduce the substrate RF loss underneath the 6-finger MOSFETs. This result indicates that high performance RF MOSFETs can be realized on plastic.

Figure 4(b) shows a comparison of measured S-parameters for 32-gate-finger $0.18 \mu \mathrm{m}$ RF MOSFETs on a VLSI-standard substrate with those after thinning down the Si substrate to 30 $\mu \mathrm{m}$, then transferring and mounting them onto plastic. Similar to the 6-gate-finger device case, both $\mathrm{S}_{11}$ and $\mathrm{S}_{22}$ are changed - due to the increased substrate impedance. However, the $S_{21}$ gain reduces slightly - maybe due to the larger area of the device that has higher ICP plasma etching damage from the substrate-thinning step.

To examine the effect of the changes in $\mathrm{S}_{21}$ we compare the RF current gain of the 32-finger $0.18 \mu \mathrm{m}$ MOSFETs before and after substrate thinning, transferal and mounting on plastic. Fig. 5 shows the RF current gain as a function of frequency. For the 32-finger $0.18 \mu \mathrm{m}$ MOSFETs on VLSIstandard Si and plastic substrates, the $\left|H_{2 I}\right|^{2}$ follows the typical $-20 \mathrm{~dB} /$ decade slope with increasing frequency. The $10 \mathrm{GHz}$ gain of the 32-finger $0.18 \mu \mathrm{m}$ MOSFET is only slightly decreased from $13.4 \mathrm{~dB}$ to $12.5 \mathrm{~dB}$, before and after thinning down, respectively. This high RF gain suggests that the RF MOSFETs are suitable for integration onto plastic. 


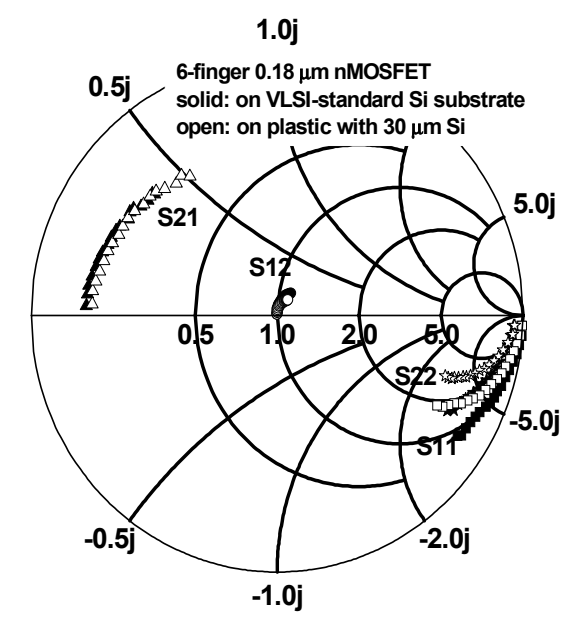

(a)

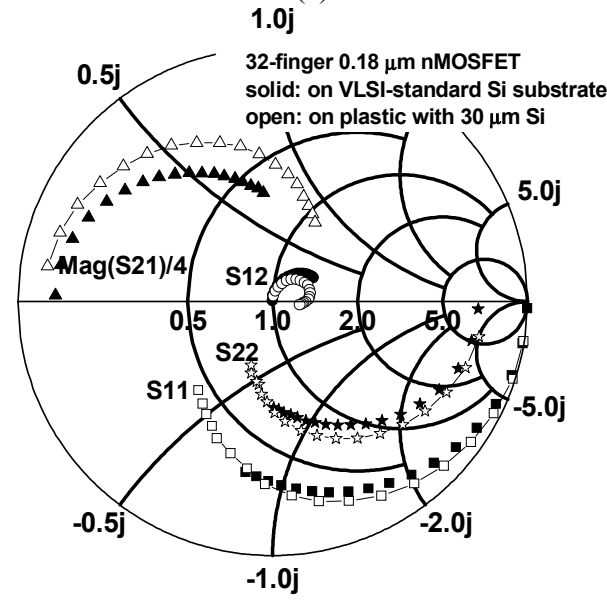

(b)

Fig. 4. Comparison of the measured S-parameters of (a) 6-finger and (b) 32-finger $0.18 \mu \mathrm{m} \mathrm{RF} \mathrm{MOSFETs,} \mathrm{before} \mathrm{(solid} \mathrm{symbols)} \mathrm{and}$ after substrate thinning to $30 \mu \mathrm{m}$, transferal and mounting on plastic (open symbols).

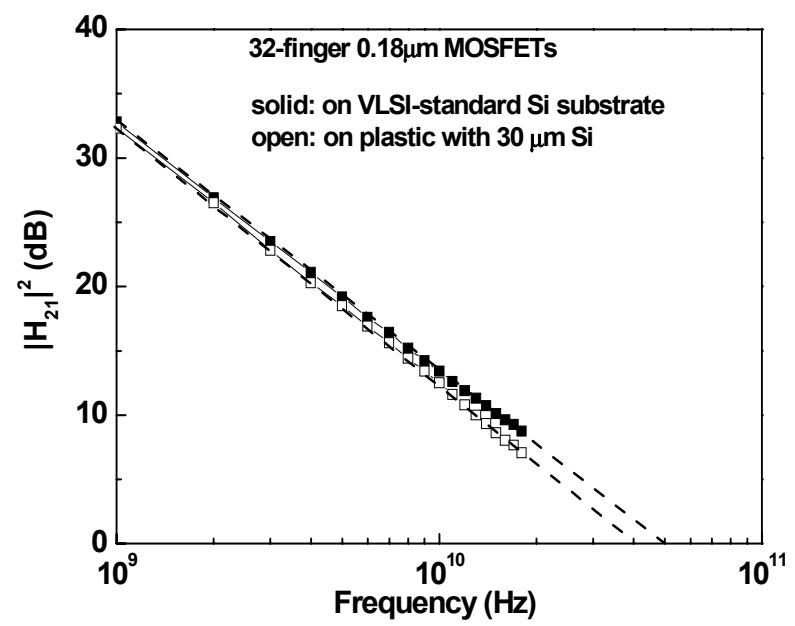

Fig. 5. Measured $\left|H_{21}\right|^{2}$ as a function of frequency for $0.18 \mu \mathrm{m}$ MOSFETs before and after substrate thinning to $30 \mu \mathrm{m}$, then transferal and mounting on plastic.
RF noise in front-end MOSFETs is normally the dominant noise source for the whole of an RF system. Figure 6 shows the measured $N F_{\min }$ and associated gain of 6-gate-finger 0.18 $\mu \mathrm{m}$ MOSFETs on plastic substrates. For comparison $N F_{\min }$ of the reference devices on VLSI-standard Si substrates are also plotted. For the devices on plastic substrates, $N F_{\min }$ is $1.2 \mathrm{~dB}$ and a high associated gain of $12.8 \mathrm{~dB}$ was measured at 10 $\mathrm{GHz}$. Only slightly better RF performance, $0.1 \mathrm{~dB}$ lower $N F_{\text {min }}$ and $0.9 \mathrm{~dB}$ higher associated gain, were obtained for the control $0.18 \mu \mathrm{m}$ MOSFETs at $10 \mathrm{GHz}$. These very small $N F_{\min }$ and associated gain differences, for the devices on plastic and on control Si substrates, are consistent with the nearly identical S-parameters shown in Fig. 4(a). In addition the DC power consumption is only $16 \mathrm{~mW}$, at the excellent low noise and high associated gain conditions.

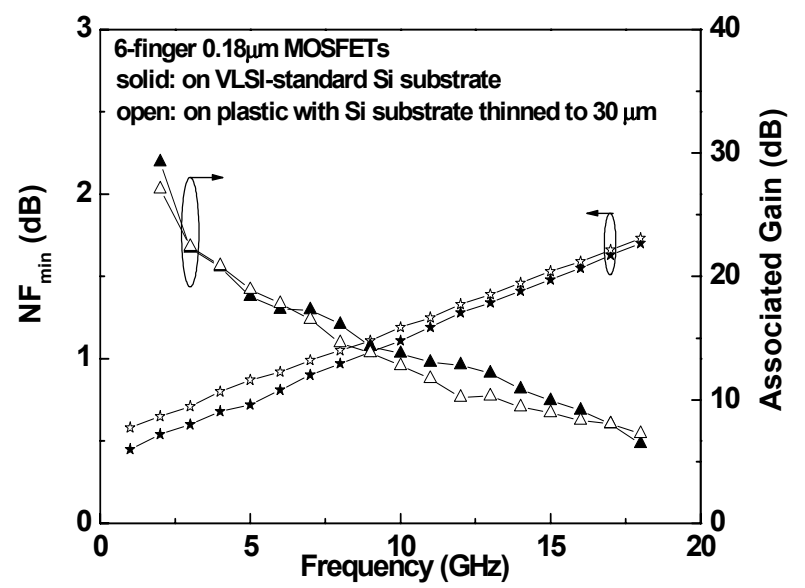

Fig. 6. Measured $N F_{\text {min }}$ and associated gain of 6-finger $0.18 \mu \mathrm{m} \mathrm{RF}$ MOSFETs on plastic and on VLSI-standard Si substrates.

\section{D. $R F$ performance improvement using mechanically- applied tensile stress}

An inherent merit of the $30 \mu \mathrm{m}$ thin Si-body RF transistors on plastic is that the flexibility permits easy application of mechanical stress [15]. Fig. 7 shows the $N F_{\text {min }}$ and associated gain of 6 -finger $0.18 \mu \mathrm{m}$ MOSFETs on plastic. Under $\sim 0.4 \%$ tensile strain, a low $N F_{\min }$ of $0.96 \mathrm{~dB}$ and high associated gain of $14.1 \mathrm{~dB}$ are shown for the $0.18 \mu \mathrm{m}$ devices on plastic at 10 $\mathrm{GHz}$, which is consistent with the increased cut-off frequency $\left(f_{t}\right)$ from 47 to $54 \mathrm{GHz}$. These values are an improvement from the unstrained case of $1.2 \mathrm{dBN} N F_{\text {min }}$ and $12.8 \mathrm{~dB}$ associated gain, and slightly better than the control devices on a VLSIstandard Si substrate.

The excellent results for RF MOSFETs on plastic, with or without tensile strain, are comparable with the best published data [13]-[14]. These very low $N F_{\min }(0.96-1.2 \mathrm{~dB})$ and high associated gain (14.1-12.8 dB) $0.18 \mu \mathrm{m}$ MOSFETs on plastic, are suitable for UWB applications. 


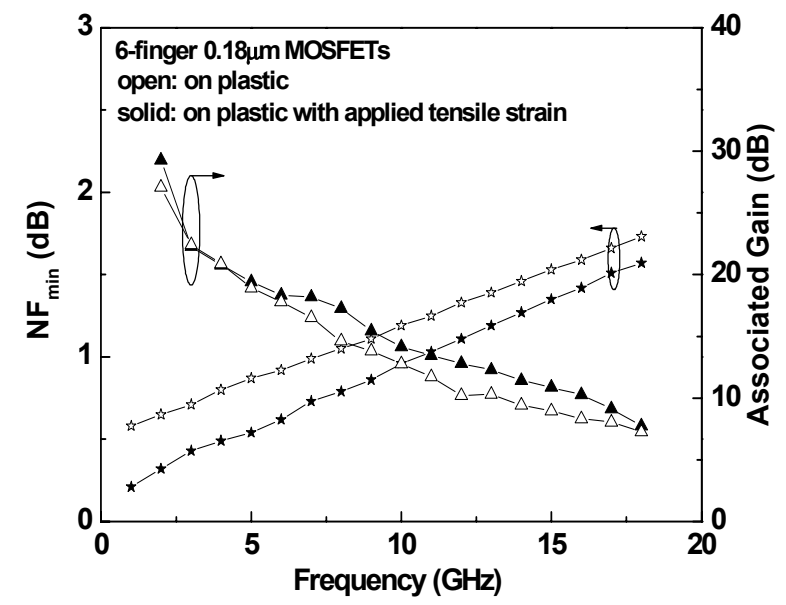

Fig. 7. Measured $N F_{\text {min }}$ and associated gain of 6-finger $0.18 \mu \mathrm{m} \mathrm{RF}$ MOSFETs on plastic, with or without mechanically-applied tensile strain $(\sim 0.4 \%)$.

\section{CONCLUSIONS}

We have demonstrated that $0.18 \mu \mathrm{m}$ MOSFETs, mounted on plastic after substrate thinning and die transfer, show low noise of $1.2 \mathrm{~dB}$ and high associated gain of $12.8 \mathrm{~dB}$, measured at $10 \mathrm{GHz}$. The high performance RF transistors, combined with high-Q passive inductors, are crucial components needed to create electronics on plastic for wireless communication applications.

\section{ACKNOWLEDGEMENT}

The authors at Univ. System of Taiwan would like to thank Director S. J. King of Microelectronic Ctr, EECS Dept., UCBerkeley for the help and G. W. Huang's group at National Nano-Device Lab. for RF measurements.

\section{REFERENCES}

[1] R. Dekker, K. Dessein, J.-H. Fock, A. Gakis, C. Jonville, O. M. Kuijken, T. M. Michielsen, P. Mijlemans, H. Pohlmann, W. Schnitt, C. E. Timmering, and A. M. H. Tombeur, "Substrate transfer: enabling technology for RF applications," Int. Electron Devices Meeting (IEDM) Tech. Dig., pp. 371-374, Dec. 2003.

[2] T. Takayama, Y. Ohno, Y. Goto, A. Machida, M. Fujita, J. Maruyama, K. Kato, J. Koyama, and S. Yamazaki, "A CPU on a plastic film substrate," Symp. on VLSI Tech., pp. 230-231, June 2004.
[3] D. S. Yu, K. T. Chan, A. Chin, S. P. McAlister, C. Zhu, M. F. $\mathrm{Li}$, and Dim-Lee Kwong, "Narrow-band band-pass filters on silicon substrates at $30 \mathrm{GHz}$," IEEE MTT-S Int. Microwave Symp. Dig., pp. 1467-1470, June 2004.

[4] A. Chin, K. T. Chan, H. C. Huang, C. Chen, V. Liang, J. K. Chen, S. C. Chien, S. W. Sun, D. S. Duh, W. J. Lin, C. Zhu, M.-F. Li, S. P. McAlister and D. L. Kwong, "RF passive devices on $\mathrm{Si}$ with excellent performance close to ideal devices designed by electro-magnetic simulation," Int. Electron Devices Meeting (IEDM) Tech. Dig., pp. 375-378, Dec. 2003.

[5] K. T. Chan, A. Chin, S. P. McAlister, C. Y. Chang, V. Liang, J. K. Chen, S. C. Chien, D. S. Duh, and W. J. Lin, "Low RF loss and noise of transmission lines on $\mathrm{Si}$ substrates using an improved ion implantation process," IEEE MTT-S Int. Microwave Symp. Dig., vol. 2, pp. 963-966, June 2003.

[6] K. T. Chan, A. Chin, Y. B. Chen, Y.-D. Lin, D. T. S. Duh, and W. J. Lin, "Integrated antennas on $\mathrm{Si}$, proton-implanted $\mathrm{Si}$ and Si-on-Quartz," Int. Electron Devices Meeting (IEDM) Tech. Dig., pp. 903-906, Dec. 2001.

[7] K. T. Chan, A. Chin, C. M. Kwei, D. T. Shien, and W. J. Lin "Transmission line noise from standard and proton-implanted Si," IEEE MTT-S Int. Microwave Symp. Dig., vol. 2, pp. 763766, June 2001.

[8] Y. H. Wu, A. Chin, K. H. Shih, C. C. Wu, S. C. Pai, C. C. Chi, and C. P. Liao, "RF loss and cross talk on extremely high resistivity $(10 \mathrm{~K}-1 \mathrm{M} \Omega-\mathrm{cm})$ Si fabricated by ion implantation," IEEE MTT-S Int. Microwave Symp. Dig., vol. 1, pp. 221-224, June 2000.

[9] T. Ohguro, K. Kojima, H. S. Momose, S. Nitta, T. Fukuda, T. Enda, and Y. Toyoshima, "Improvement of high resistivity substrate for future mixed analog-digital application," Symp. On VLSI Tech. Dig., pp. 158-159, June 2002.

[10] P. Blondy, A.R. Brown, D. Cros, G. M. Rebeiz, "Low loss micromachined elliptic filters for millimeter wave telecommunication systems," IEEE MTT-S Int. Microwave Symp., pp. 1181-1184, June 1998.

[11] S. Pacheco, C. T.-C. Nguyen, and L. P. B. Katehi, "Micromechanical electrostatic K-band switches," IEEE MTTS Int. Microwave Symp. Dig., pp. 1569-1572, June 1998.

[12] E.-C. Park, S.-H. Baek, T.-S. Song, J.-B. Yoon, and E. Yoon, "Performance Comparison of $5 \mathrm{GHz}$ VCOs Integrated by CMOS Compatible High Q MEMS Inductors," IEEE MTT-S Int. Microwave Symp., pp. 721-724, June 2003.

[13] M.C. King, Z. M. Lai, C. H. Huang, C. F. Lee, M. W. Ma, C. M. Huang, Y. Chang and Albert Chin, "Modeling finger number dependence on RF noise to $10 \mathrm{GHz}$ in $0.13 \mu \mathrm{m}$ node MOSFETs with $80 \mathrm{~nm}$ gate length," IEEE RF IC Symp. Dig., pp. 171-174, June 2004.

[14] M. C. King, M. T. Yang, C. W. Kuo, Y. Chang, and A. Chin, "RF noise scaling trend of MOSFETs from $0.5 \mu \mathrm{m}$ to $0.13 \mu \mathrm{m}$ technology nodes," IEEE MTT-S Int'l Microwave Symp. Dig., vol. 1, pp. 6-11, June 2004.

[15] R. E. Belford, W. Zhao, J. Potashnik, Q. Liu, and A. Seabaugh, Performance-augmented CMOS using back-end uniaxial strain," Device Research Conference (DRC) Dig., pp. 41-42, June 2002. 